Mens

revue d'histoire intellectuelle de l'Amérique française

Madeleine Landry et Robert Derome. L'art sacré en Amérique

française. Le trésor de la Côte-de-Beaupré. Paris et Sillery, Nouveau monde et Septentrion, 2005. 207 p.

\title{
Richard Gauthier
}

Volume 7, numéro 2, printemps 2007

URI : https://id.erudit.org/iderudit/1024131ar

DOI : https://doi.org/10.7202/1024131ar

Aller au sommaire du numéro

Éditeur(s)

Centre de recherche en civilisation canadienne-française

ISSN

1492-8647 (imprimé)

1927-9299 (numérique)

Découvrir la revue

Citer ce compte rendu

Gauthier, R. (2007). Compte rendu de [Madeleine Landry et Robert Derome. L'art sacré en Amérique française. Le trésor de la Côte-de-Beaupré. Paris et Sillery, Nouveau monde et Septentrion, 2005. 207 p.] Mens, 7(2), 334-337.

https://doi.org/10.7202/1024131ar d'utilisation que vous pouvez consulter en ligne.

https://apropos.erudit.org/fr/usagers/politique-dutilisation/ 
ne parvient pas vraiment à rendre intelligibles ces débats sur la démocratie, son anthologie rend tout de même bien compte de leur complexité et de leur intensité, et démentit à elle seule cette légende selon laquelle les Canadiens français du temps auraient été complètement imperméables à l'idée et aux pratiques démocratiques. Lévesque nous promet un deuxième volet à cette enquête, une anthologie des débats sur les pratiques démocratiques au Québec de la fin du XIX ${ }^{\mathrm{e}}$ siècle à nos jours. On souhaite qu'il y préserve l'esprit de ce premier volet, mais qu'il peaufine son analyse.

Dominique Foisy-Geoffroy

Département d'bistoire

Université Laval

\section{Madeleine Landry et Robert Derome. L'art sacré en Amérique française. Le trésor de la Côte-de- Beaupré. Paris et Sillery, Nouveau monde et Septentrion, 2005. 207 p.}

Magnifiquement illustré, le dernier livre dẻ Madeleine Landry et Robert Derome intitulé L'art sacré en Amérique française. Le trésor de la Côte-de-Beaupré est publié de part et d'autre de l'Atlantique. La plume des deux auteurs y est des plus élégantes et accessibles. La lecture est continuellement accompagnée par des explications d'une très grande clarté et judicieusement illustrées. D'ailleurs, la succession des images et des tableaux didactiques ponctuant le texte est telle que l'on serait porté à se dire " oui, je vois! » pour manifester son aisance à comprendre. Non seulement l'expert y trouvera son compte dans ce livre présentant d'une manière synthétique 
l'état des connaissances dans le domaine, mais toute personne qui débute en histoire de l'art y trouvera son profit.

Le choix du titre marque la référence initiale, le point de départ d'une aventure culturelle qui ne perd pas de vue ses origines, tout en assumant le deuil de ce monde ancien, dont témoignent encore les fragments existants sur lesquels les deux auteurs se penchent. Il y avait de l'art sacré, il y a maintenant du patrimoine religieux. Il y avait le rêve d'une Amérique qui soit française, il y a encore une présence francophone en Amérique du Nord. Il y a donc de l'hétérogénéité et l'on ne finit pas de chercher à traduire adéquatement cet héritage culturel imprégné de religieux, dans une société devenue sécularisée et pluraliste.

Le livre de Landry et Derome expose le trésor des églises des quatre paroisses de la Côte-de-Beaupré qui datent du régime français, soit celles de Château-Richer, de L'Ange-Gardien, de Sainte-Anne-de-Beaupré et de Saint-Joachim. Au fil des pages, ils adoptent une méthode qui s'avère convaincante et gagnerait à être utilisée pour d'autres régions du Québec. À partir d'une bonne explication du contexte originel ainsi que de l'histoire des églises des quatre vieilles paroisses, les auteurs recensent méticuleusement l'histoire du décor et des objets d'art qui ont ennobli le culte. Peu à peu, une sorte de puzzle apparait aux yeux du lecteur. Il en résulte que le livre fournit une vision d'ensemble de ce qui reste du trésor de la Côte-deBeaupré, tel un "musée imaginaire » comme les deux auteurs se plaisent à le mentionner en citant Malraux.

Dans leur livre, tout part des églises des quatre vieilles paroisses de la Côte-de-Beaupré. Un chapitre leur est consacré, en expliquant les allongements et élargissements successifs ainsi que les travaux de reconstruction. S'ensuit un deuxième chapitre sur les décors intérieurs des églises, certainement un chapitre parmi les plus captivants du livre avec le 
troisième qui traite des tabernacles (le tabernacle étant le foyer central vers lequel tout converge, conformément aux décrets du concile de Trente du milieu du XVI ${ }^{\mathrm{e}}$ siècle). Quant aux deux derniers chapitres, le quatrième et le cinquième, ils font respectivement état des tableaux et de l'orfèvrerie de valeur qui ont survécu aux aléas de la mode et aux ravages du temps. Transversalement à tous ces chapitres, s'intercalent des explications sur un point ou l'autre qui mérite une attention particulière. Un peu de vocabulaire de base y est également inculqué ou rappelé. L'à-propos de ces ajouts est à saluer. Somme toute, même si la découpe des chapitres n'apparaît pas très nettement, en partie à cause des explications supplémentaires (distribuées comme en aparté) et des nombreuses illustrations, les enchaînements, eux, sont des plus logiques. On dirait que les deux auteurs nous accompagnent pas à pas, en nous prenant par la main.

Par ailleurs, il se pourrait que le livre L'art sacré en Amérique française. Le trésor de la Côte-de-Beaupré aide à faire des brèches dans les impasses actuelles en histoire de l'art, au moins sous trois angles différents. Premièrement, parce qu'il dépasse la dialectique raidie par les deux procès de L'AngeGardien dans les années 1980, lesquels tendaient à opposer le monde paroissial au monde muséal, c'est-à-dire, d'une part, l'environnement naturel de l'objet d'art dit sacré et, d'autre part, son arrachement aux fins d'une protection étatique. En réponse, le « musée imaginaire » qui apparait dans le livre combine les deux mondes, en acceptant assez bien le deuil de l'église comme seul cadre intégrateur d'un tel trésor. Le lecteur ne s'en aperçoit peut-être pas, et nous ne savons pas dans quelle mesure les deux auteurs en sont eux-mêmes conscients, mais leur approche nous apparait prometteuse pour le patrimoine - ce champ du savoir trop souvent cantonné à un discours romantique peu ou prou réactionnaire à la modernité. 
Deuxièmement, l'approche de Landry et Derome questionnerait aussi le rôle des experts. Habituellement, ces derniers traitent d'une école, d'un architecte, d'un artiste, d'un monument et d'un objet en repérant des correspondances avec d'autres écoles, architectes, artistes, monuments et objets. Bien sûr, la communauté concrète qui a promu et protégé au jour le jour l'effort artistique n'est pas oubliée, mais souvent négligée. Or, la perspective des auteurs a le mérite de nous river à l'histoire locale, à son imaginaire et à sa fierté légitime. Si ce n'est pas déjà dans l'air, une exposition thématique sur le trésor de la Côte-de-Beaupré qui soit complémentaire au livre serait à envisager. Une telle initiative pourrait avoir lieu à la basilique Sainte-Anne-de-Beaupré ou être itinérante dans les quatre églises paroissiales. Nous pressentons que les citoyens concernés s'y plairaient, sans compter l'intérêt que manifesteraient les visiteurs et les pèlerins. En tout cas, cela serait dans l'esprit du livre. Enfin, et troisièmement, le livre de Landry et Derome n'est pas spécialement voué à l'avancée des connaissances. Il s'appuie surtout sur du matériel déjà connu des experts. Sa force réside davantage dans la manière de présenter le savoir accumulé et, sous cet angle, il est efficace.

En terminant, nous ne pouvons passer sous silence que la plupart des travaux parmi les plus fondamentaux utilisés par les deux auteurs commencent à dater et que beaucoup des experts qui les ont rédigés vieillissent. Préoccupés, nous nous permettons d'être inquiets pour la relève dans un champ du savoir qui a besoin d'affronter les défis du $\mathrm{XXI}^{\mathrm{e}}$ siècle.

Richard Gautbier

Chaire de recherche du Canada en patrimoine urbain $U Q A M$ 